\title{
Towards a nanostructured thermoelectric generator using ion-track lithography
}

\author{
E Koukharenko ${ }^{1}$, X Li $^{2}$, I Nandhakumar ${ }^{2}$, N Frety ${ }^{3}$, S P Beeby ${ }^{1}$, D Cox ${ }^{4}$, \\ M J Tudor ${ }^{1}$, B Schiedt ${ }^{5}$, C Trautmann ${ }^{5}$, A Bertsch ${ }^{6}$ and N M White ${ }^{1}$ \\ ${ }^{1}$ University of Southampton, Southampton, UK \\ ${ }^{2}$ School of Chemistry, Southampton, UK \\ ${ }^{3}$ Institut Charles Gerhardt-Equipe PMOF Université Montpellier II, France \\ ${ }^{4}$ Advanced Technology Institute, University of Surrey, UK \\ ${ }^{5}$ GSI, Materialforschung, Darmstadt, Germany \\ ${ }^{6}$ EPFL FSTI LMIS4 Lausanne, Switzerland \\ E-mail: ak@ecs.soton.ac.uk
}

Received 13 April 2008, in final form 30 July 2008

Published 29 September 2008

Online at stacks.iop.org/JMM/18/104015

\begin{abstract}
This paper presents the process development towards a new generation of nanostructured thermoelectric generators for power harvesting from small temperature gradients by using a combination of traditional silicon microfabrication techniques, electroplating and submicron ion-track nanolithography. Polyimide nanotemplates with pore diameters ranging from $30 \mathrm{~nm}$ to $120 \mathrm{~nm}$ were fabricated. Preliminary results from the fabrication of poly(methyl methacrylate) (PMMA)-nanostructured templates are reported. $\mathrm{Bi}_{2} \mathrm{Te}_{3}$ nanowires ( 80 and $120 \mathrm{~nm}$ diameters) were electroplated into polyimide ion-track nanotemplates. $\mathrm{Bi}_{2} \mathrm{Te}_{3}$ nanowires of a R3 m structure, with preferential orientation in (1 10 ) crystallographic plans, were electroplated. The chemical composition of $\mathrm{Bi}_{2} \mathrm{Te}_{3}$ with nearly stoichiometric composition $\left(\mathrm{Bi}_{2.31} \mathrm{Te}_{3}\right)$ was obtained. Homogeneity profiles of the chemical composition were obtained. A fine-grained observed microstructure $(6-10 \mathrm{~nm})$ and (1 110$)$ crystalline orientation were obtained, which is extremely promising for improving the thermoelectric material properties. The thermoelectric properties of the $\mathrm{Bi}_{2} \mathrm{Te}_{3}$-electroplated thin films (Seebeck coefficient $\alpha$ ) and electrical resistivity of the $\mathrm{Bi}_{2} \mathrm{Te}_{3}$ bundle nanowires were found to be $-52 \mu \mathrm{V} \mathrm{K}^{-1}$ and $\sim 14 \mathrm{M} \Omega \mathrm{cm}$, respectively. Polyimide (Kapton foil) and PMMA 950 photoresists were promising materials for the realization of a nanostructured thermoelectric generator on flexible and rigid substrates, respectively.
\end{abstract}

(Some figures in this article are in colour only in the electronic version)

\section{Introduction}

Nanostructured materials have attracted great interest in recent years because they exhibit unique physical, chemical and mechanical properties, which have extensive potential applications [1, 2]. The significantly different physical properties of these novel materials have been explained by their characteristic structural features, which are in between isolated atoms and bulk macroscopic materials [3]. In particular, the exceptional electronic, mechanical, optical, magnetic and thermoelectric (TE) properties of the nanoscale materials are due to the effect of quantum confinement, which can be attributed to the changes in the total energy and structure of the system [4]. For this reason, 1D nanostructures have a profound impact on nanoelectronics, nanodevices and alternative energy resources. Nearly every class of traditional material has a 1Dnanostructure counterpart.

The motivation of this work is to contribute to one of the great challenges in the twenty-first century: the development of alternative energy sources. In response to the needs of modern society and emerging ecological concerns, it is essential that new, low-cost and environmentally friendly energy conversion and storage systems are found. Additionally, the rapid increase in the development of remote 
wireless devices, embedded structures and portable electronics demonstrates the need for self-sufficient local power sources. The powering of wireless devices from energy harvested from the environment (e.g. solar, wind, vibration and TE) presents an alternative to batteries, which are bulky and contain a finite amount of energy. Thermoelectric power generation presents many advantages including solid-state operation with no moving parts, long life ( $\sim 20$ years) and high reliability [5]. The drawbacks of existing thermoelectric generators are low efficiency and large size [5].

The efficiency of TE materials is determined using the figure of merit $\mathrm{ZT}=\left(\alpha^{2} T / \rho K_{T}\right)$, where $\alpha, T, \rho$ and $K_{T}$ are the Seebeck coefficient, absolute temperature, electrical resistivity and thermal conductivity, respectively [5]. To maximize the thermoelectric figure of merit (ZT) of a material, large thermopower (absolute value of the Seebeck coefficient), high electrical conductivity and low thermal conductivity are required. Therefore, the performance of these devices depends on the properties of the materials. One of the crucial parameters to be considered in order to improve the thermoelectric properties of the material is their optimum microstructural properties (e.g. grain size, chemical composition and composition homogeneity across a sample). A highly homogenous material will yield improved thermoelectric properties [6, 7]. It has also been previously shown that the grain size has a significant effect on the phonon mean-free path by offering a potentially more favourable carrier scattering mechanism and a much lower lattice thermal conductivity, thus providing the potential for improved thermoelectric devices [8]. Rowe et al proposed that scattering at the grain boundaries might be an effective way to improve the efficiency of thermoelectric materials [9].

The best TE materials commercially available today are $\mathrm{Bi}_{2-x} \mathrm{Sb}_{x} \mathrm{Te}_{3}$ based, which have a ZT of $\sim 0.9$ at room temperature. However, nanostructured materials have recently attracted great interest because theoretical studies have predicted that efficiency is increased by a factor of $\sim 3$ if the thermoelectric element's 'leg' diameter can be decreased to a size at which quantum confinement and interface scattering effects occur [10].

In order to fabricate thermoelectric devices from $\mathrm{Bi}_{2-x} \mathrm{Sb}_{x} \mathrm{Te}_{3}$ nanostructures, various traditional methods, such as laser ablation, solution-based synthesis, vapourphase growth, thermal evaporation methods and vacuumbased techniques such as metal organic vapour deposition (MOVPD), molecular beam epitaxy (MBE) including liquid phase epitaxy have been used [11-15]. All these methods require either complex parameter optimization or/and are very expensive, and most of them are not compatible with silicon microfabrication processes.

Currently, template-based synthesis has attracted great interest to miniaturize thermoelectric materials using micro/nano-templates from porous alumina, microphotolithography or e-beam lithography [16-19]. Although these techniques offer the unique advantages of a precise size and shape control to fabricate nanowires, these methods have limitations in size, density of thermoelectric elements, complexity and high cost [20,21].
The current state-of-the-art, presented by Snyder et al [18], is a micro-thermoelectric $\mathrm{Bi}_{2-x} \mathrm{Sb}_{x} \mathrm{Te}_{3}$ device fabricated by conventional MEMS techniques. This has a limited number of TE elements of $20 \mu \mathrm{m}$ in length and $60 \mu \mathrm{m}$ in diameter, and generates a maximum power of $\sim 1 \mu \mathrm{W}$, which is insufficient for most of today's wireless sensor applications.

More recently, the fabrication of $\mathrm{Bi}$ and $\mathrm{Bi}_{2-x} \mathrm{Sb}_{x} \mathrm{Te}_{3}$ $(x=1.5)$ thermoelectric nanowires has been done by using templates by ion-track irradiation lithography [22, 23]. This technique uses heavy accelerated ions as a source to damage the material, making it susceptible to chemical etching in the direction defined by the irradiation. In the past, this method has been used to evaluate the effect of heavy charged particles on solids, i.e. radiation-induced changes to mechanical, rheological, optical and electrical properties $[24,25]$. Different polymers, such as cellulose acetate, dimethyl siloxane, formophenol, polyester, polycarbonate, polyethylene, polyvinyl acetate, were reported in nuclear studies [26]. It has been discovered that ion-track technology can produce low-cost templates for nanowires with a diameter $<50 \mathrm{~nm}$ and with a high aspect ratio (>1000) [27], and it is a very promising technology for the fabrication of nanostructured devices. Also, it is important to integrate iontrack technology as a part of standard silicon microfabrication batch processes. Hence, only a limited number of polymers can be used and, to date, only polyimide and poly(methyl methacrylate) (PMMA) are compatible with both ion-track technology and MEMS processes.

The pore geometry of etched tracks in polyimide has been extensively investigated [28-31], using the $\mathrm{NaOCl}$ etching solution at various $\mathrm{pH}$ levels. It was found that the $\mathrm{pH}$ value of the etchant plays a crucial role in the selectivity of track etching and the shape of the resulting pores, which depends on both alkalinity and hypochlorite content of the solution. However, there is still an opportunity to decrease the pores' track diameter by using pre-etching chemicals. Vilensky et al reported that the use of a strong oxidizer, such as $\mathrm{H}_{2} \mathrm{O}_{2}$, can significantly increase the etch rate in polyimide and lead to a formation of a smaller pore size [32]. This in turn will lead to a formation of the higher aspect ratio nanostructures.

In the case of PMMA, little research has been done on nanostructured templates by ion-track irradiation. Doobeli et al used a very thin layer of $85 \mathrm{~nm}$ of PMMA irradiated with $\mathrm{MeV} \mathrm{C}$, Ge and I ions that yielded nanopores with diameters between 18 and $45 \mathrm{~nm}$ after development [33]. Mistry et al [34] and Alves et al [35] investigated the effect of the ion-beam lithography on the PMMA thin films using $\mathrm{MeV}$ protons for lithography applications. No work has been reported to date on the process development of a suitably thick layer of PMMA in order to reach higher aspect ratio structures.

This paper discusses the development of thermoelectric nanostructures produced by combining the traditional silicon microfabrication techniques with electroplating and submicron ion-track nanolithography for use in a thermoelectric microgenerator, suitable for power harvesting from small temperature gradients. As discussed previously, polyimide and PMMA have been evaluated as the nanostructured templates for $\mathrm{Bi}_{2-x} \mathrm{Sb}_{x} \mathrm{Te}_{3}$ ( $x$ from 0 to 2) 


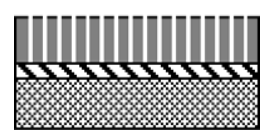

(a) Nanotemplate into polymer by iontrack irradiation

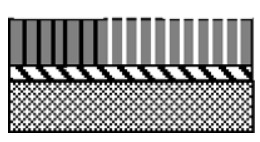

(c) $\mathbf{B i}_{2} \mathbf{T} \mathbf{e}_{3}, \mathbf{n}$-type thermoelement electroplating

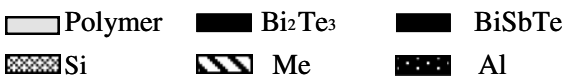

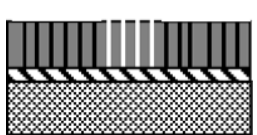

(b) BiSbTe, p-type

thermoelement

electroplating

Figure 1. Process flow.

nanowire electroplating. In addition to their compatibility with silicon microfabrication processes, they can be used on both rigid and flexible substrates, and the pore diameters of the nanotemplates can be controlled to achieve an average diameter size of less than $50 \mathrm{~nm}$. This work presents the electroplating parameters for $\mathrm{Bi}_{2} \mathrm{Te}_{3}$ nanowires of $80-120 \mathrm{~nm}$ into polyimide-nanostructured templates and the development of PMMA-based nanostructured templates. It also reports nanostructures characterization results such as phase analysis, chemical composition and grain size for $\mathrm{Bi}_{2} \mathrm{Te}_{3}$ nanowires. Preliminary results of the Seebeck coefficient were investigated on thin $\mathrm{Bi}_{2} \mathrm{Te}_{3}$-electroplated films, and electrical properties of the $\mathrm{Bi}_{2} \mathrm{Te}_{3}$ bundle nanowires are reported.

\section{Experiment}

\subsection{Microfabrication process}

A schematic diagram of the thermoelectric nanostructured generator process flow is shown in figure 1. A thin layer of metal is evaporated onto an oxidized Si wafer, which acts as a seed layer for $\mathrm{Bi}-\mathrm{Sb}-\mathrm{Te}$ electroplating. This is followed by a deposition of a thick layer $(20 \mu \mathrm{m})$ of polyimide or $10 \mu \mathrm{m}$ of PMMA. The polymer layers are then exposed to the ion-track irradiation, damaging the material into the parallel track directions. The next step involves wet etching of the irradiated films to open up the nanopores. This stage is followed by photolithography in order to define the areas for n-type $\mathrm{Bi}_{2} \mathrm{Te}_{3}$ electroplating. Next, n-type $\mathrm{Bi}_{2} \mathrm{Te}_{3}$ nanowires are electroplated. Then, another photolithography is realized to define the moulds for p-type $\mathrm{Bi}_{2-x} \mathrm{Sb}_{x} \mathrm{Te}_{3}$ electroplating and to mask the areas with n-type $\mathrm{Bi}_{2} \mathrm{Te}_{3}$-electroplated structures. Once p-type $\mathrm{Bi}_{2-x} \mathrm{Sb}_{x} \mathrm{Te}_{3}$ nanowire arrays are electroplated, an aluminium layer is evaporated and patterned to form the upper interconnect layers between individual TE elements. The polyimide template is then removed 'freeing' the $\mathrm{Bi}_{2} \mathrm{Te}_{3}$ and $\mathrm{Bi}_{2-x} \mathrm{Sb}_{x} \mathrm{Te}_{3}$ nanoelements. Kapton can be successfully removed by using an $\mathrm{N}$-methylpyrrolidone (NMP)-based solvent without affecting the structural stability of the device. In the case of the PMMA, standard solvents such as acetone or iso-propyl-alcohol (IPA) can be successfully used. Alternatively, a flexible version of the generator may be produced by using the low thermal conductivity Kapton as the main structural support.

\section{Results}

\subsection{Polyimide nanotemplate etching}

All polyimide samples were irradiated with $\mathrm{Pb}$ projectiles of $\sim 2.3 \mathrm{GeV}$ kinetic energy and fluences of $5 \times 10^{8}$ or $5 \times$ $10^{9}$ ions $\mathrm{cm}^{-2}$ at the heavy ion accelerator Unilac at the GSI (Darmstadt). We have studied track etching in polyimide PI2731 wet-type photoresists from HD Microsystems and also dry films of Kapton HN from Dupont of $12.7 \mu \mathrm{m}$ thickness. Both were spun on/laminated to silicon substrates with and without $200 \mathrm{~nm}$ of a gold seed layer for the subsequent electroplating process. Kapton HN foils of $20 \mu \mathrm{m}$ thickness were also investigated.

Samples irradiated with $5 \times 10^{8}$ ions $\mathrm{cm}^{-2}$ and $5 \times$ $10^{9}$ ions $\mathrm{cm}^{-2}$ were pre-etched in an $\mathrm{H}_{2} \mathrm{O}_{2}$ solution at $60{ }^{\circ} \mathrm{C}$ or $90{ }^{\circ} \mathrm{C}$ and subsequently etched in a sodium hypochlorite $(\mathrm{NaOCl})(13 \%, \mathrm{pH} \sim 12.6)$ solution at $60{ }^{\circ} \mathrm{C}$. The resulting pores were observed using scanning electron microscopy (SEM) (figures 2 and 3). Depending on the nature of etched polyimide (wet or dry type), etching time, temperature of the solutions $\left(\mathrm{H}_{2} \mathrm{O}_{2}, \mathrm{NaOCl}\right)$ and $\mathrm{pH}$ of $\mathrm{NaOCl}$, the pore diameter varied between $30 \mathrm{~nm}$ and $120 \mathrm{~nm}$ for different samples of polyimide.

Typically, the smallest pore sizes of $30-50 \mathrm{~nm}$ were observed for PI2731, wet-type photosensitive polyimide. However, the adhesion of the wet polyimide onto gold-coated silicon substrates was poor, and further studies on the chemical activation of the gold surface to improve the adhesion between metal and polymer layers are needed.

\subsection{PMMA template etching}

Two types of PMMA polymers have been used for nanostructured template fabrication: PMMA foil $(50 \mu \mathrm{m}$ thick from Goodfellow) and PMMA wet photoresist (950A11 from Microchem). PMMA layers of $10 \mu \mathrm{m}$ were spun onto the $\mathrm{Au} / \mathrm{Cr}$ surface of silicon wafers. All PMMA samples were then irradiated with $\mathrm{U}^{+}$ions (kinetic energy of 


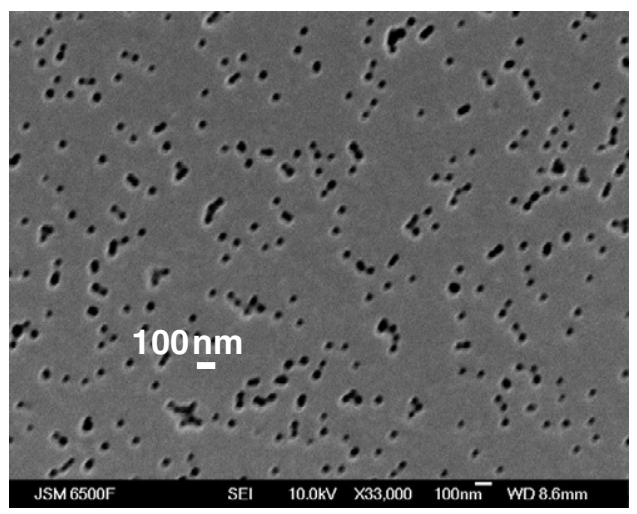

(a)

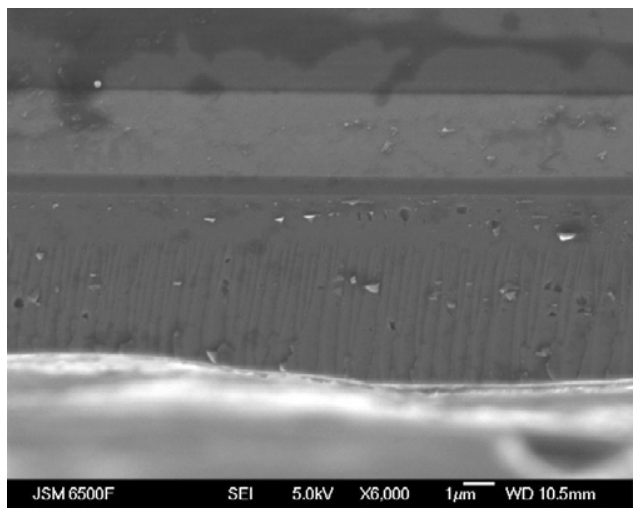

(b)

Figure 2. SEM of polyimide, $5 \times 10^{9}$ ions $\mathrm{cm}^{-2}$ (PI2731, $10 \mu \mathrm{m}$ thick), ion-track etched, 40 min in $\mathrm{H}_{2} \mathrm{O}_{2}\left(60{ }^{\circ} \mathrm{C}\right)$ followed by $5 \mathrm{~min}$ in $\mathrm{NaOCl}\left(60^{\circ} \mathrm{C}\right)$. Pore diameters from 30 to $50 \mathrm{~nm}$. (a) Top view. (b) Cross-section.

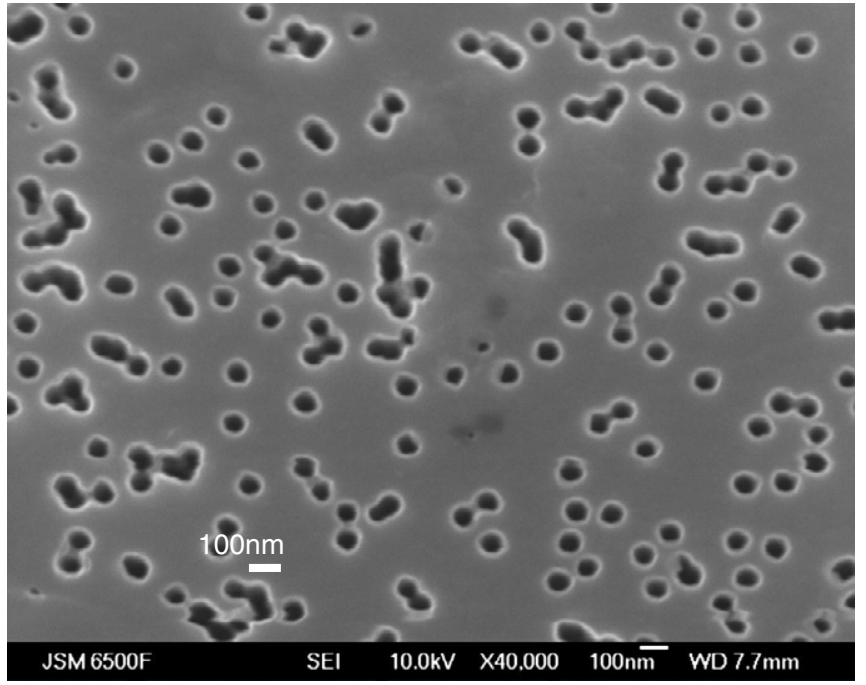

Figure 3. SEM of polyimide (Kapton, $12.7 \mu \mathrm{m}$ thick), $5 \times 10^{9}$ ions $\mathrm{cm}^{-2}$ (Kapton, $12.7 \mu \mathrm{m}$ thick), ion-track irradiated and etched for 40 min in $\mathrm{H}_{2} \mathrm{O}_{2}\left(60{ }^{\circ} \mathrm{C}\right)$ followed by $5 \mathrm{~min}$ in $\mathrm{NaOCl}\left(60{ }^{\circ} \mathrm{C}\right)$. Pore diameters from 80 to $120 \mathrm{~nm}$.

11.4 MeV/nucleon and fluences of $10^{8}$ or $5 \times 10^{9}$ ions $\mathrm{cm}^{-2}$ ) at the heavy ion accelerator Unilac at the GSI (Darmstadt). Two wet etch solutions were evaluated with the ion-trackirradiated substrates. These were a methyl-iso-butyl-ketone MIBK-based developer (MIBK/IPA) and the 'GG' developer system (a mixture of water and three different organic solvents: $15 \mathrm{vol} \%$ water, $60 \mathrm{vol} \%$ butoxy-ethoxyethanol, $20 \mathrm{vol} \%$ tetrahydro-oxazine and 5 vol\% aminoethanol). Both solutions were used at room temperature and constantly mixed on an electromechanical shaker to ensure a uniform wet-etch process. This resulted in the best conditions, a faster development rate and a smoother developed surface. For the PMMA photoresist, these etches resulted in pore diameters of $<30 \mathrm{~nm}$ (for the MIBK:IPA solution) and ranged from 30 to $50 \mathrm{~nm}$ (for the GG solution) (see figures 4 and 5).

This leads to features with an aspect ratio of about 1000:1. For the PMMA foils (50 $\mu \mathrm{m}$ thick), wet-etched pore diameters ranging from 25 to $100 \mathrm{~nm}$ were achieved with the GG

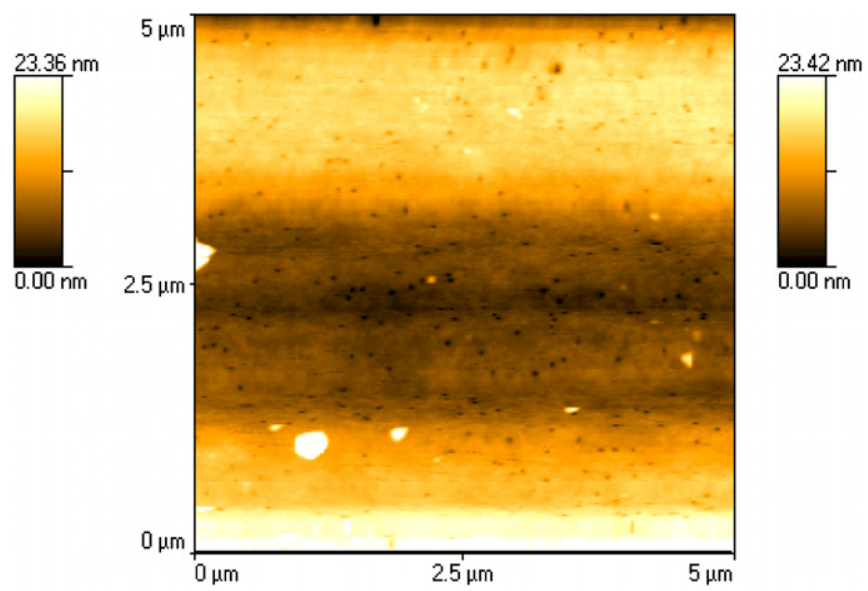

Figure 4. AFM scan of PMMA $95010 \mu \mathrm{m}$ thick, $10^{9}$ ions $\mathrm{cm}^{-2}$ ion-track irradiated and etched, $1 \mathrm{~h}$ etch in a GG developer. Pore diameters from 30 to $50 \mathrm{~nm}$.

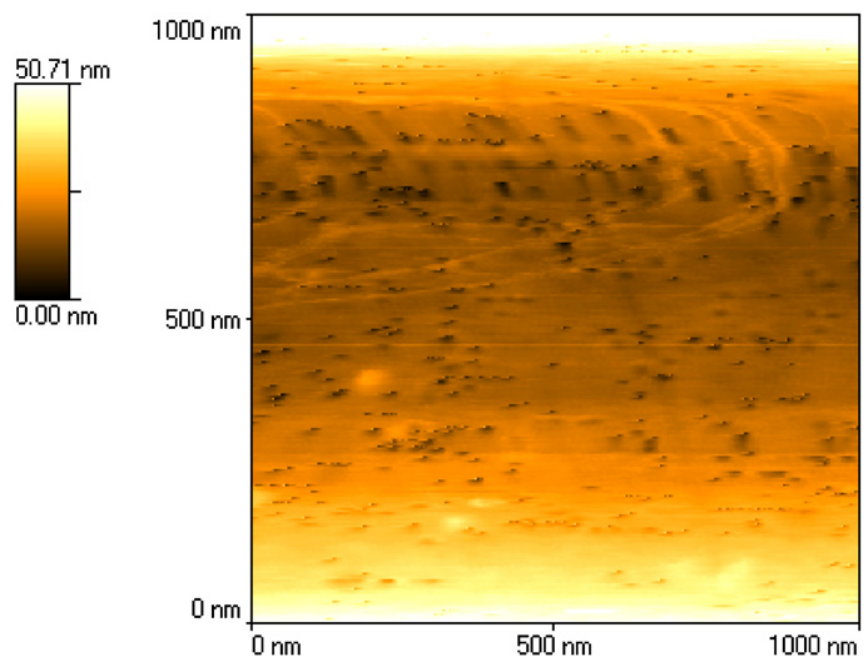

Figure 5. AFM of PMMA $95010 \mu \mathrm{m}$ thick, $10^{9}$ ions $\mathrm{cm}^{-2}$, ion-track irradiated and etched, $1 \mathrm{~h}$ etch in an MIBK:IPA developer. Pore diameters of $<30 \mathrm{~nm}$. 


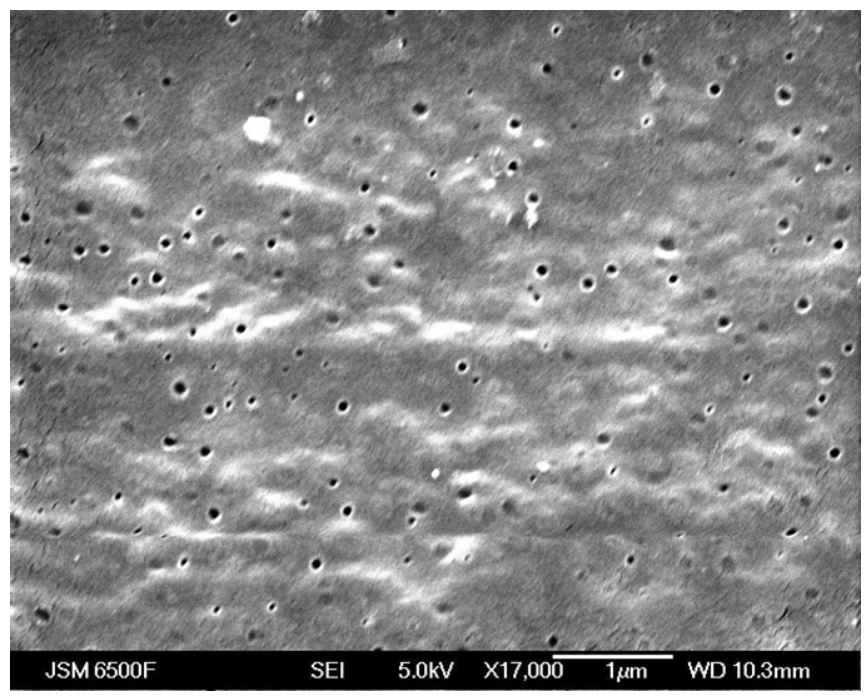

Figure 6. SEM of PMMA foil $50 \mu \mathrm{m}$ thick, $10^{8}$ ions $\mathrm{cm}^{-2}$ ion-track irradiated and etched, $4 \mathrm{~h}$ etch in a GG developer. Pore diameters range from 25 to $100 \mathrm{~nm}$.

developer (see figure 6). This study showed that the PMMA 950 photoresist results in higher aspect ratio structures and with good adhesion to the gold-coated silicon substrate.

To image the openings of holes etched along the ion tracks and confirming that the PMMA is sensitive to the development solutions mentioned, the track openings were analysed by atomic force microscopy (AFM) in a non-contact mode. Measurements were carried out with a commercial microscope (Veeco Explorer) operating in air. A high aspect ratio $\mathrm{Si}$ nanowhisker cantilever has been utilized to perform a quantitative analysis of the holes which are up to $45 \mathrm{~nm}$ in diameter.

\subsection{Bi-Te nanowire electroplating}

Electroplating of $\mathrm{Bi}_{2} \mathrm{Te}_{3}$ nanowires into polyimide templates was carried out by cathodic electrochemical co-deposition of bismuth and tellurium powder dissolved in the aqueous nitric acid using a three-electrode cell with

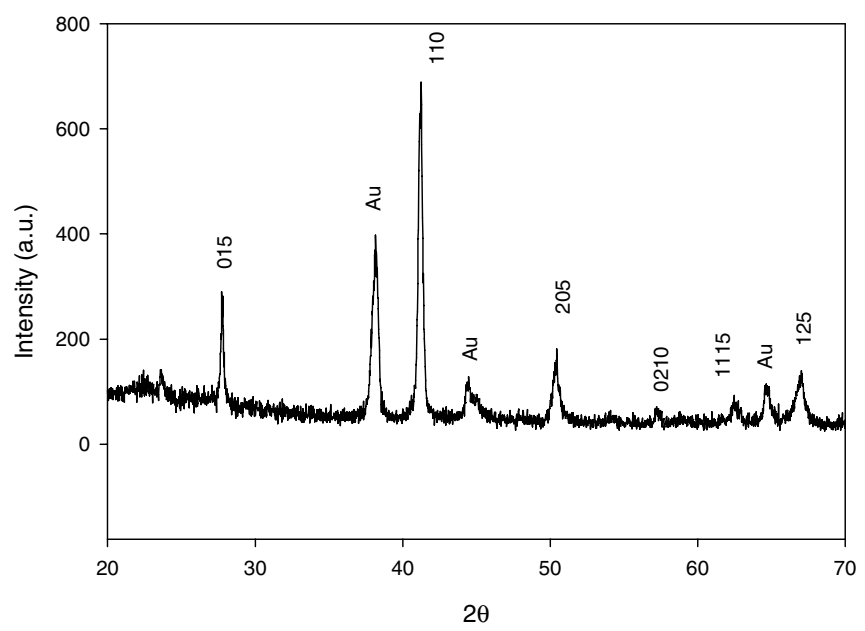

Figure 8. XRD of $\mathrm{Bi}_{2} \mathrm{Te}_{3}$ nanowire composition by electroplating.

an Autolab potentiostat/galvanostat. It was found that the electrodeposition conditions (such as current density, deposition potential and temperature) have a significant effect on the $\mathrm{Bi}_{2} \mathrm{Te}_{3}$ nanostructure and morphology. The samples were electrodeposited in the plating bath at room temperature. For a range of applied potentials from $-0.22 \mathrm{~V}$ to $0.03 \mathrm{~V}$ versus a saturated calomel electrode (SCE), the resulting $\mathrm{Bi}_{2} \mathrm{Te}_{3}$ compounds show a stoichiometric composition. Figure 7 shows $\mathrm{Bi}_{2} \mathrm{Te}_{3}$ nanowires electroplated into polyimide nanostructured templates. It can be seen that the average diameter of the nanowires is about $80-120 \mathrm{~nm}$, which is consistent with the pore size of the polyimide template.

\subsection{Bi-Te nanowire microstructural characterization}

The grain size of the $\mathrm{Bi}_{2} \mathrm{Te}_{3}$ nanowires was characterized using a JSM-6500F scanning electron microscope operating at $20 \mathrm{kV}$. The crystal structures of $\mathrm{Bi}_{2} \mathrm{Te}_{3}$ nanowires were investigated using a Siemens D5000 x-ray diffractometer with $\mathrm{Cu} \mathrm{K} \alpha$ radiation $(\lambda=1.5406 \AA)$. Wide-angle $\mathrm{x}$-ray diffraction spectroscopy (XRD) spectra revealed that the deposited nanowires have a rhombohedral structure, R3 m (figure 8).

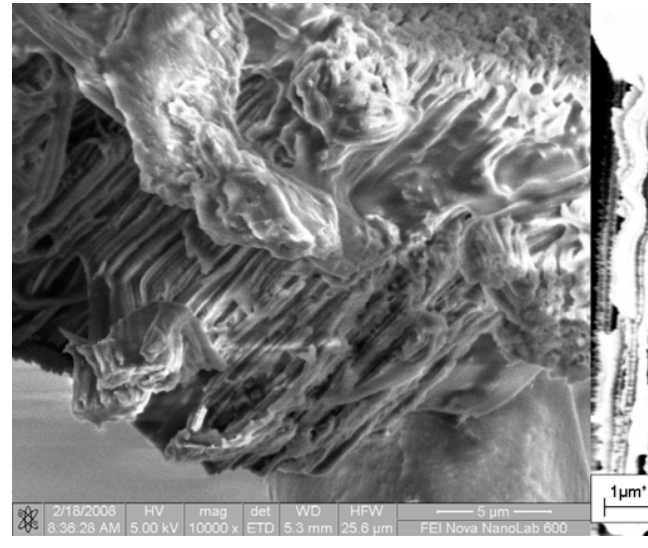

(a)

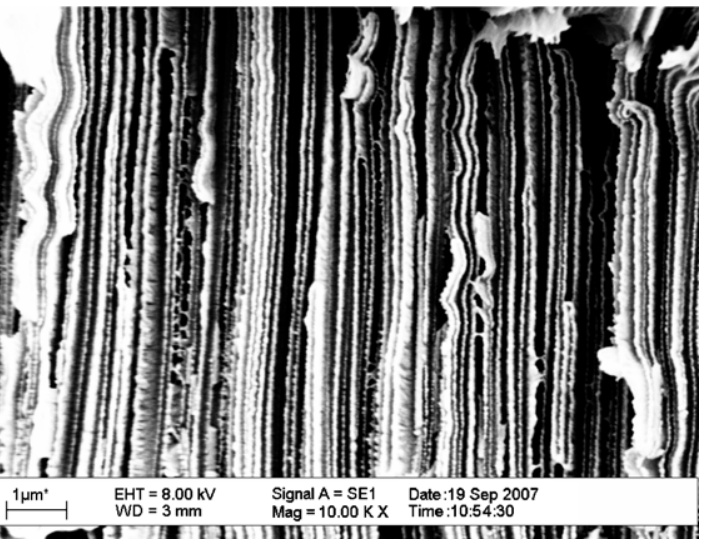

(b)

Figure 7. SEM image of a cross section of $\mathrm{Bi}_{2} \mathrm{Te}_{3}$ nanowires deposited at $-0.2 \mathrm{~V}$ versus $\mathrm{SCE}$ at room temperature into a polyimide template with a pore diameter of $80 \mathrm{~nm}$ to $120 \mathrm{~nm}$. (a) $5 \mu \mathrm{m}$ scale, (b) $1 \mu \mathrm{m}$ scale. 


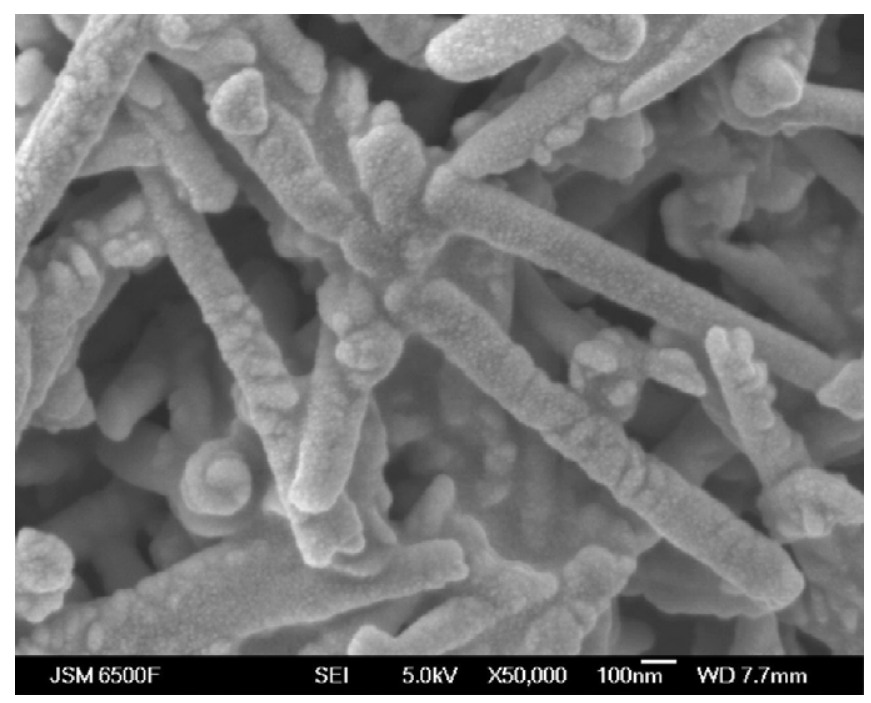

Figure 9. SEM image of $\mathrm{Bi}_{2} \mathrm{Te}_{3}$ nanowires showing their grain structure.

Table 1. Chemical composition of $\mathrm{Bi}_{2} \mathrm{Te}_{3}$-electroplated film surfaces by EDS and microprobe analyses.

\begin{tabular}{lcc}
\hline \multicolumn{3}{c}{ Theoretical formulation $\mathrm{Bi}_{2} \mathrm{Te}_{3}$} \\
\hline Type of analyses & Microprobe & EDS \\
\hline Bi concentration (at\%) & 43.37 & 40.95 \\
Sb concentration (at\%) & 0.4 & 0 \\
Te concentration (at\%) & 56.24 & 59.05 \\
Analysed composition & $\mathrm{Bi}_{2.31} \mathrm{Te}_{3}$ & $\mathrm{Bi}_{2} \mathrm{Te}_{3}$ \\
\hline
\end{tabular}

The standard ICDD PDF card data (82-0358) has been used to identify and index all detected peaks as those belonging to the $\mathrm{Bi}_{2} \mathrm{Te}_{3}$ crystal with the space group $\mathrm{R} 3 \mathrm{~m}$ except for the peaks of $\mathrm{Au}$, which come from the gold seed layer that was used as a working electrode. Therefore, a polycrystalline single-phase $\mathrm{Bi}_{2} \mathrm{Te}_{3}$ compound was successfully electroplated. According to SEM observations, the electroplated nanowires appeared to have a very fine microstructure with a grain size of the order of tens of nanometres as shown in figure 9 .

\subsubsection{Chemical composition analyses. The chemical} composition of $\mathrm{Bi}_{2} \mathrm{Te}_{3}$ films and nanowires was determined using energy dispersive spectrometry (EDS) with accuracy measurement of $\sim 5 \%$, the analysed volume being of the order of $\mu \mathrm{m}^{3}$ from the surface. In order to study the homogeneity of the chemical composition across the film surface, microprobe analysis (Cameca, Castaing) on a raw electroplated film surface has been used. The accuracy of the measurements is $\sim 0.1 \%$ and the analysed volume is in the order of $1 \mu \mathrm{m}^{3}$. The chemical composition of $\mathrm{Bi}_{2} \mathrm{Te}_{3}$ films and nanowires by EDS gave a constant Te content of $\sim 59.05$ at $\%$ and a $\mathrm{Bi}$ content of 40.95 at $\%$, which is nearly stoichiometric. The chemical composition by microprobe analyses of the binary $\mathrm{Bi}_{2} \mathrm{Te}_{3}$ showed a $\mathrm{Bi}$ excess (table 1 ). The volume analysed by the microprobe corresponded to a thickness of the order of $1 \mu \mathrm{m}$ from the film surface.

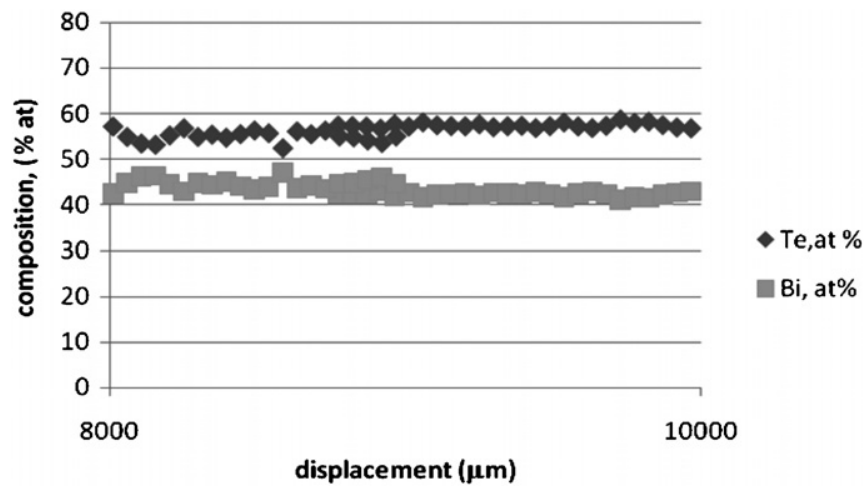

Figure 10. Microprobe profiles of $\mathrm{Bi}_{2} \mathrm{Te}_{3}$-electroplated film surface.

These deviations from the nominal composition match previous observations [12, 36-38]. According to Horak et al, this can be explained by native defects (antisite type) in the $\mathrm{Bi}_{2} \mathrm{Te}_{3}$ structure: in the crystal lattice an excess of $\mathrm{Bi}$ atoms takes the place of the $\mathrm{Te}^{\mathrm{II}}$ sites and thus there is the formation of the defects antisite $\mathrm{Bi}^{\prime} \mathrm{Te}$. Miller and Li showed experimentally that defects of the antisite type predominate in samples with $\mathrm{AN}$ excess of $\mathrm{Bi}$ [39]. This type of $\mathrm{Bi}_{2} \mathrm{Te}_{3}$ compound is considered quasi-stoichiometric [12]. The studies by Eyidi et al showed that the default structure in $\mathrm{Bi}_{2} \mathrm{Te}_{3}$ extends up to between 2 and $20 \mu \mathrm{m}$ in depth [40]. This suggests that a small deviation from the stoichiometric composition can be typically observed in the superficial layer of this material, and varies from one type of thin technology fabrication technique to another. In fact, non-homogeneity of the evolution of the chemical composition through the sample thickness was observed previously [41, 42]. However, this deviation can be solved by the annealing of the native structural defects.

The homogeneity of the chemical composition of $\mathrm{Bi}_{2} \mathrm{Te}_{3}$ across the electroplated surface was determined from microprobe analysis profiles. Microprobe profiles of $\mathrm{Bi}$ (at\%) and $\mathrm{Te}(\mathrm{at} \%)$ are reported in figure 10 . The variations in the concentration of $\mathrm{Bi}(\mathrm{at} \%)$ and $\mathrm{Te}(\mathrm{at} \%)$ across the samples are in the range of $3 \%$, which is an acceptable value for $\mathrm{Bi}_{2-x} \mathrm{Sb}_{x} \mathrm{Te}_{3}$ compounds [43, 44]. Massalsky's phase diagram showed that the homogeneity for the chemical compound $\mathrm{Bi}_{2} \mathrm{Te}_{3}$ falls into a range of 52-65 at\% [44]. These profiles evidenced the chemical composition homogeneity along the surface of the $\mathrm{Bi}_{2} \mathrm{Te}_{3}$ samples. These chemical composition results show that for binary $\mathrm{Bi}_{2} \mathrm{Te}_{3}$ alloys, the electroplating technique can be used to reach the stoichiometry and achieve a homogeneous distribution of the elements across the surface. This chemical homogeneity is an important parameter for the performance of thermoelectric materials.

\subsection{Thermoelectric properties of $\mathrm{Bi}_{2} \mathrm{Te}_{3}$-electroplated structures}

The Seebeck coefficient $\alpha\left(\mu \mathrm{V} \mathrm{K}^{-1}\right)$ was determined using a custom-made Seebeck measurement unit, which was calibrated against a reference standard. The measurement accuracy is $5 \%$, using a polycrystalline $\mathrm{Bi}$ foil as a reference standard. The system was calibrated using copper-constantan 


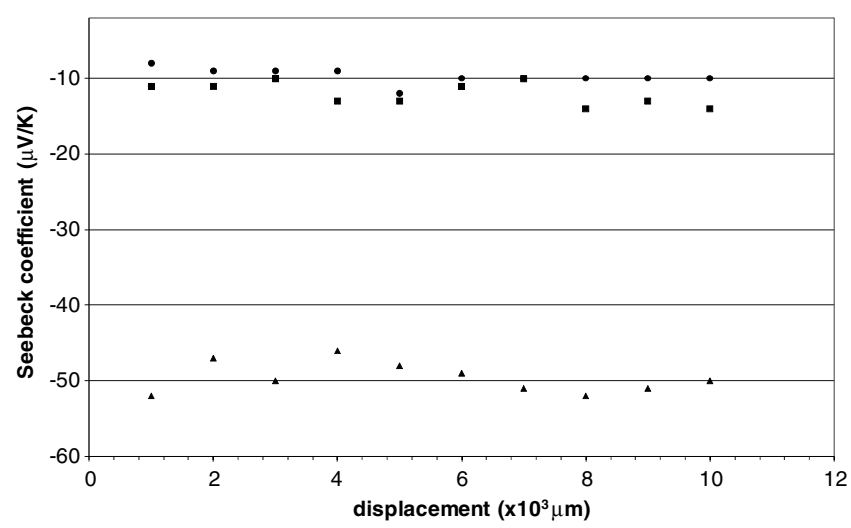

Figure 11. Seebeck coefficient profiles for $\mathrm{Bi}_{2} \mathrm{Te}_{3}$-electroplated films.

thermocouples and a high precision Keithley DMM 2000/E digital multimeter with $0.1 \%$ accuracy.

The Seebeck coefficient profile was measured along the surface of various raw electroplated $\mathrm{Bi}_{2} \mathrm{Te}_{3}$ film samples, and the profiles are reported in figure 11. These profiles evidence the uniformity of the Seebeck coefficient across the surface of the $\mathrm{Bi}_{2} \mathrm{Te}_{3}$ samples. The Seebeck coefficient of the $\mathrm{Bi}_{2} \mathrm{Te}_{3}$ film had a negative value, which shows n-type of the semiconductor. The maximum value of the Seebeck coefficient for a raw $\mathrm{Bi}_{2} \mathrm{Te}_{3}$-electroplated film was $-52 \mu \mathrm{V} \mathrm{K}^{-1}$. Annealing treatments can further improve these values by eliminating various faults in the crystalline structures, which are typical for $\mathrm{Bi}_{2-x} \mathrm{Sb}_{x} \mathrm{Te}_{3}$ compounds.

The $I-V$ characteristic of the $\mathrm{Bi}_{2} \mathrm{Te}_{3}$ bundle nanowires was measured by a four-terminal method at room temperature (300 K) using the microscope FEI nova nanolab 600 dual beam FIB. The maniplution system was a Zyvex 4 probe system. The tips used for the probes were electropolished tungsten prepared by dc etching, and the measurement system was a Keithley 4200-SCS semiconductor characterization system.

The bundle consisted of $\mathrm{Bi}_{2} \mathrm{Te}_{3}$ nanowires with a thickness of $20 \mu \mathrm{m}$ and a width of $80-120 \mathrm{~nm}$.

The typical $I-V$ curve of a $\mathrm{Bi}_{2} \mathrm{Te}_{3}$ bundle is shown in figure 12(a), which shows linear behaviour confirming good
Ohmic contact with the nanowires. The part of the nonlinearity of the $I-V$ characteristics may be due to the potential barrier formed by contacting the sample with a metal wire. From this curve the resistance of the specimen can be estimated to be $\sim 27 \mathrm{G} \Omega$ (at $I=0.3 \mathrm{nA}$ ), which corresponded to an electric resistivity of $\sim 14 \mathrm{M} \Omega \mathrm{cm}$. The high value of the electric resistivity can be due to the mechanical damage of nanowires during the sample preparation for measurements.

\section{Discussion}

Our investigations on electrochemically deposited wires reveal that the crystallinity and texture can be controlled by the deposition parameters. $\mathrm{Bi}_{2} \mathrm{Te}_{3}$ nanowires grown potentiostatically are (110) textured and agree with the results reported by Chaouni et al [45]. SEM associated with energy-dispersive spectrometry, $\mathrm{x}$-ray diffraction, evidenced a microcrystalline structure with a single phase of $\mathrm{Bi}_{2} \mathrm{Te}_{3}$ with a preferential crystalline orientation in (1 110$)$ plans, which is the preferred texture for maximizing the thermoelectric properties of $\mathrm{Bi}_{2} \mathrm{Te}_{3}$ alloys.

The homogeneity of the chemical composition analysis showed that in the case of binary $\mathrm{Bi}_{2} \mathrm{Te}_{3}$ alloys, the electroplating technique can achieve a close to stoichiometric chemical composition and an acceptable homogeneous distribution (within 3\%) of the elements across the surface. This chemical homogeneity is an important parameter for the performance of thermoelectric materials. In order to achieve a stoichiometric chemical composition, thermal treatment of the samples will be realized to anneal native structural defects of this material; electroplating parameters can also be further optimized. The fine-grained observed microstructure of $6-10 \mathrm{~nm}$ is promising for enhanced thermoelectric material properties, by way of reducing the thermal conductivity.

The high electrical resistivity of the $\mathrm{Bi}_{2} \mathrm{Te}_{3}$ bundle nanowires can be due to the mechanical damage of the nanostructures while preparing samples for measurements. Thermoelectric properties of $\mathrm{Bi}_{2} \mathrm{Te}_{3}$ can be improved by thermal treatment by annealing various defaults of the microcrystalline structure. (a)

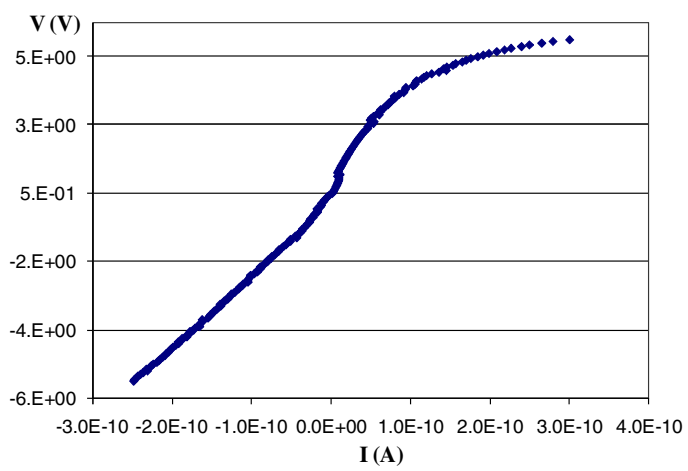

(b)

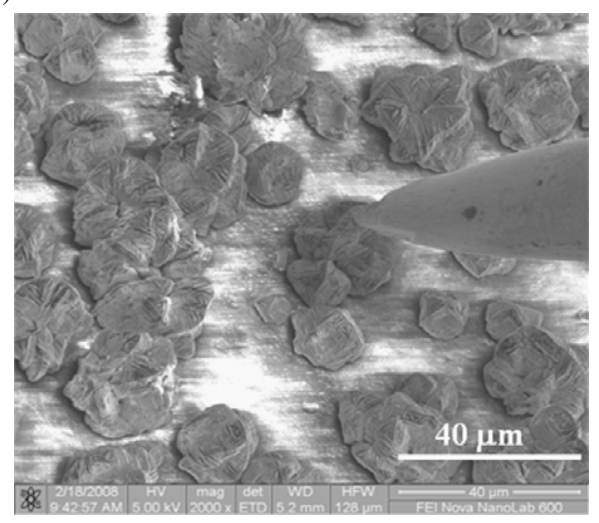

Figure 12. (a) $I-V$ curve of a $\mathrm{Bi}_{2} \mathrm{Te}_{3}$ bundle into polyimide. (b) $\mathrm{Bi}_{2} \mathrm{Te}_{3}$ bundle nanowires using the Zyvex nanomanipulator. 


\section{Conclusions}

Polyimide (Kapton foil) and PMMA 950 photoresists were found to be promising materials for the realization of a nanostructured thermoelectric generator on flexible and rigid substrates, respectively. These materials are suitable for the fabrication of ion-track nanostructured templates which have been successfully used to form electroplated BiSbTe nanowires, which in turn make up thermoelectric nanostructured generators integrated with silicon microfabrication processes. Polyimide nanotemplates with $30-120 \mathrm{~nm}$ pore diameters were fabricated and the PMMA templates yielded $<30-100 \mathrm{~nm}$ pores. $\mathrm{Bi}_{2} \mathrm{Te}_{3}$ electroplating of nanowires (80 and $120 \mathrm{~nm}$ diameters) was carried out into a polyimide (Kapton $20 \mu \mathrm{m}$ ) iontrack template. $\mathrm{Bi}_{2} \mathrm{Te}_{3}$ of the $\mathrm{R} 3 \mathrm{~m}$ structure with close to stoichiometry composition has been deposited with the grain preferential orientation in (1 110$)$ and fine grain size $(6-10 \mathrm{~nm})$ for optimal thermoelectric properties. An acceptable homogeneity of chemical composition across the surface of the $\mathrm{Bi}_{2} \mathrm{Te}_{3}$ film (within $3 \%$ of variation) was achieved by the lowcost electroplating technique. Optimization of electroplating parameters to decrease the deviation from the stoichiometry, annealing of the structural defects and study of the evolution of the chemical composition through the electrodeposited $\mathrm{Bi}_{2} \mathrm{Te}_{3}$ film thickness using different microstructural characterization techniques are underway.

Further improvements of the adhesion between the polyimide and Au seed layer are currently being investigated. The etching parameters of an ion-track-irradiated PMMA foil require further optimization to ensure that etching occurs through the entire thickness of the film.

The thermoelectric properties of $\mathrm{Bi}_{2} \mathrm{Te}_{3}$-electroplated thin films were measured. Future work will include the measurement of the $\mathrm{Bi}_{2} \mathrm{Te}_{3}$ nanowire microstructural and thermoelectric properties.

\section{Acknowledgments}

$\mathrm{Mr} \mathrm{Z}$ Webber from the Southampton University Nanoprototype facility is acknowledged for the assistance in performing AFM scans on the PMMA 950 layers. This work was supported by the EPSRC (EP/D076250).

\section{References}

[1] He G, Eckert J, Loser W and Schultz L 2002 Novel Ti-base nanostructure-dendrite composite with enhanced plasticity Nature Mater. 2 33-7

[2] Kuchibhatla S V N T, Karakoti A S, Bera D and Seal S 2007 One dimensional nanostructured materials Program. Mater. Sci. 52699

[3] Arico A S, Bruce P, Scrosati B, Tarascon J M and Van Schalkwijk W 2005 Nanostructured materials for advanced energy conversion and storage devices Nature Mater. 4 366-77

[4] Law M, Goldberger J and Yang P 2004 Annu. Rev. Mater. Res. 3483

[5] Rowe D M 1995 CRC Handbook of Thermoelectrics (Boca Raton, FL: CRC Press)
[6] Fleurial J P, Borschevsky M A, Ryan M A, Phillips W, Kolawa E, Kacisch T and Ewell R 1997 Proc. 16th Int. Conf. Thermoelectrics (Dresden, Germany) pp 641-6

[7] Ivanova L D, Brovikova S A, Zusmann G and Rainshaus P 1994 Inorg. Mater. 30 770-5

[8] Harman T C, Taylor P J, Walsh M P and LaForge B E 2002 Science 297 2229-32

[9] Rowe D M, Shukla V S and Savvides N 1981 Nature 2905809

[10] Hicks L D and Dresselhaus M S 1993 Use of quantum-well superlattices to obtain a high figure of merit from nonconventional thermoelectric materials Appl. Phys. Lett. 63 3230-3

[11] Watanabe N, Kawamata J and Toshima N 2004 Preparation of protected nanoparticles of bismuth telluride by laser ablation in solution Chem. Lett. 33 1368-9

[12] Goltsman V M, Kudinov V A and Smirnov I A 1972 Semiconducting Thermoelectric Materials Based on $\mathrm{Bi}_{2} \mathrm{Te}_{3}$ (Moskow: Nauka)

[13] Mader S 1965 Metastable alloy films J. Vac. Sci. Technol. 2 35-41

[14] Giani A, Pascal-Delannoy F, Boyer A, Foucaran A, Gschwind M and Ancey P 1997 Elaboration of $\mathrm{Bi}_{2} \mathrm{Te}_{3}$ by metal organic chemical vapor deposition Thin Solid Films 303 1-3

[15] Cho S, Kim Y, DiVenere A, Wong G K, Ketterson J B and Meyer J R 1999 Antisite defects of $\mathrm{Bi}_{2} \mathrm{Te}_{3}$ thin films Appl. Phys. Lett. 751401

[16] Xiaochuan X, Lidong C, Chunfen W, Qin Y and Chude F 2005 Template synthesis of heterostructured polyaniline $/ \mathrm{Bi}_{2} \mathrm{Te}_{3}$ nanowires J. Sol. State Chem. 178 2163-6

[17] Wang W-L, Wan C-C and Wang Y-Y 2006 Investigation of electrodeposition of $\mathrm{Bi}_{2} \mathrm{Te}_{3}$ nanowires into nanoporous alumina templates with a rotating electrode J. Phys. Chem. B 110 12974-80

[18] Snyder J G, Lim J R, Huang C-K and Fleurial J P 2003 Thermoelectric microdevice fabricated by a MEMSlike electrochemical process Nature Mater. 2 528-31

[19] Chen C L, Chen Y Y, Chen C T, Harutyunyan S R, Lai S J, Chen C D and Lin S J 2008 Thermoelectric properties of $\mathrm{Bi}_{2} \mathrm{Te}_{3}$ films and nanowire arrays American Physical Society (APS) 2008 March Meeting (10-14 March) abstract \#H20.009

[20] Fert A and Piraux L 1999 Magnetic nanowires J. Magn. Magn. Mater. $200338-58$

[21] Woo L, Ran J I, Go U, Sele and Nielsch K 2006 Fast fabrication of long-range ordered porous alumina membranes by hard anodization Nature Mater. 5 741-7

[22] Yoo B, Xiao F, Bozhilov K N, Herman J, Ryan M A and Myung N V 2007 Electrodeposition of thermoelectric superlattice nanowires Adv. Mater. 19 296-9

[23] Toimil Molares M E, Chtanko N, Cornelius T W C, Dobrev D, Enculescu1 I, Blick R H and Neumann R 2004 Fabrication and contacting of single Bi nanowires Nanotechnology 15 S201-7

[24] Fleischer R L, Price P B and Walker R M 1975 Nuclear Tracks in Solids (Berkeley, CA: University of California Press)

[25] Biederman H and Slavinska D 1998 Ion bombardment of organic materials and its potential application Proc. 1998 Int. Conf. Ion Implantation Technology (Kyoto, Japan) vol 2 pp 815-9

[26] Fischer B E and Sporh R 1983 Production and use of nuclear tracks: imprinting structure on solids Rev. Mod. Phys. 55 907-48

[27] Lindeberg M and Hjort K 2004 A comprehensive study of ion track enabled high aspect ratio microstructures in flexible circuit boards Microsyst. Technol. 10 608-21 
[28] Trautmann C, Brüchle W, Spohr R, Vetter J and Angert N 1996 Pore geometry of etched ion tracks in polyimide $\mathrm{Nucl}$. Instrum. Methods B 111 70-4

[29] Trautmann C, Bouffard S and Spohr R 1996 Etching threshold for ion tracks in polyimide Nucl. Instrum. Methods B $116429-33$

[30] Skupinski M, Toulemonde M, Lindeberg M and Hjort K 2005 Ion tracks developed in polyimide resist on $\mathrm{Si}$ wafers as template for nanowires Nucl. Instrum. Methods Phys. Res. B 240 681-9

[31] Klintberg L, Lindeberg M and Thornell G 2001 Sodium hypochlorite as a developer for heavy ion tracks in polyimide Nucl. Instrum. Methods Phys. Res. B 184 536-43

[32] Vilensky A L, Oleinikov V A, Markov N G, Mchedishvili B V and Dontsova E P 1994 Polyimide track membranes for ultrafiltration and microfiltration Polym. Sci. 36 391-9

[33] Doobeli M, Ames F, Musil C R, Scandella L, Suter M and Synal H A 1998 Surface tracks by MeV C60 impacts on mica and PMMA Nucl. Instrum. Methods Phys. Res. B $143503-12$

[34] Mistry P, Gomez-Morilla I, Grime G W, Webb R, Jeynes C, Gwilliam R, Cansell A, Merchant M and Kirkby K J 2005 New developments on the Surrey microbeam applications to lithography Nucl. Instrum. Methods Phys. Res. B $231428-32$

[35] Alves A, Reichart P, Siegele R, Johnston P N and Jamieson D N 2006 Ion beam lithography using single ions Nucl. Instrum. Methods Phys. Res. B 249 730-3
[36] Rowe D M 2006 Thermoelectrics Handbook Macro to Nano (Boca Raton, FL: CRC Press)

[37] Stary Z, Horak J, Stordeur M and Stolzer M 1988 Antisite defects in $\mathrm{Sb}_{2-x} \mathrm{Bi}_{x} \mathrm{Te}_{3}$ mixed crystals J. Phys. Chem. Solids 49 29-34

[38] Horak J, Cermak K and Koudelka L 1986 Energy formation of antisite defects in doped $\mathrm{Sb}_{2} \mathrm{Te}_{3}$ and $\mathrm{Bi}_{2} \mathrm{Te}_{3}$ crystals $J$. Phys. Chem. Solids 47 805-9

[39] Miller G R and C-Y Li 1965 Evidence for the existence of antistructure defects in bismuth telluride by density measurements J. Phys. Chem. Solids 26 173-7

[40] Eyidi D, Maier D, Eibl O and Westphal M 1998 Defects of $\mathrm{Bi}_{2} \mathrm{Te}_{3}$ Peltier device structures Phys. Status Solidi a $187585-600$

[41] Koukharenko E, Frety N, Shepelevich V G and Tedenac J C 2001 Microstructural characterization of ultrarapid quenched bismuth and antimony tellurides alloys J. Cryst. Growth 222 773-8

[42] Naletov V L and Bazhenov D R 1992 Proc. 3rd Int. Workshop on Thermoelectric Materials pp 22-3

[43] Mudry S I 1998 The structure of liquid $\mathrm{Bi}_{2} \mathrm{Te}_{3}$ alloys near the stoichiometric region J. Alloys Comp. 267 100-4

[44] Massalsky T 1988 Binary Alloys Phase Diagrams vol 1 (Metals Park, OH: American Society for Metals)

[45] Chaouni H, Bessières J, Modaressi A and Heizmann J J 2000 Texture prediction of $\mathrm{Bi}_{2} \mathrm{Te}_{3}$ electroplated layers using Hartman's theory of crystal growth J. Appl. Electrochem. 30 419-27 